\title{
Hepcidina, una nueva proteína en la homeostasis del hierro
}

Del Castillo Rueda A, De Portugal Álvarez. J. Hepcidina, una nueva proteína en la homeostasis del hierro. An Med Interna (Madrid) 2003; 20: 605-606.

La hepcidina fue descrita por primera vez como LEAP-1 (liver-expresed antimicrobial peptide 1) en 2000 (1) y un año más tarde se correlacionó en el metabolismo del hierro junto a otros genes y proteínas, ya como hepcidina (HEPC) (2), hasta que recientemente se le ha dado un valor de primer orden en la homeostasis del hierro, lo que ha permitido definir la sobrecarga de hierro por su déficit y la anemia inflamatoria por su exceso $(3,4)$.

La proteína antimicrobiana hepática, hepcidina, péptido implicado en el control de la absorción intestinal del hierro, fue así denominada en 2001 al aislarse en orina humana un péptido sintetizado por el hígado (hep-), con propiedades antimicrobianas (antifúngica y antibacteriana) in vitro (-cidin) (5). Actualmente se la conoce también como HAMP (hepcidin antimicrobial peptide; OMIM 606464) (6). El gen, localizado en el cromosoma 19, codifica un propéptido de 84 aminoácidos del que por acción enzimática derivan las formas activas C-terminal con 20, 22 y 25 aminoácidos que son ricos en cisteína. La hepcidina mayor es un péptido catiónico con 25 aminoácidos y 4 puentes disulfuro que unen los 8 residuos de cisteína y que determinan su actividad en los 17 aminoácidos que delimitan $(5,7,8)$.

Las alteraciones en el metabolismo del hierro son las enfermedades más frecuentes y los estudios carenciales de este metal han monopolizado la atención en detrimento de las situaciones de sobrecarga. Sin embargo, se ha demostrado que en cuanto a la prevalencia de la patología marcial, en una población de 1.300 personas elegidas al azar, en Cataluña, el $7 \%$ de varones presenta déficit de hierro mientras que más del $15 \%$ presenta sobrecarga y, a pesar de que, como era de esperar, la presencia de sobrecarga férrica es inferior en mujeres, este porcentaje se iguala después de la menopausia (9). Así mismo, en una población de 1.016 personas mayores, de entre 67 y 96 años, incluida en el estudio de Framingham, se comprobó que sólo un $2,7 \%$ presentaba déficit de hierro frente a un $13 \%$ que tenía sobrecarga (10).

En el estudio de la homeostasis del hierro se han implicado en los últimos años diversos genes y proteínas entre los que la hepcidina puede ser el principal responsable del control de la absorción intestinal de hierro y su utilización por los macró- fagos $(6,7,11,12)$. La síntesis de hepcidina por los hepatocitos se inicia tras la liberación de citoquinas en los sinusoides hepáticos activados por microorganismos y/o saturación elevada de transferrina (8). La hepcidina en sangre inhibe la absorción de hierro en el duodeno y su liberación por los macrófagos; su eliminación urinaria está aumentada en pacientes con sobrecarga de hierro, infecciones y enfermedades inflamatorias y se correlaciona con niveles séricos de ferritina que dispone de los mismos estímulos patogénicos: la inflamación y la sobrecarga de hierro $(8,13)$.

La hemocromatosis, enfermedad genética más frecuente en la población humana de origen caucasiano, se define como un trastorno heredado del metabolismo del hierro que condiciona un aumento de su absorción intestinal y posterior depósito progresivo en células parenquimatosas, en el contexto de un complejo tramado genotípico (14). Las formas clínicas más frecuentes se asocian a mutaciones del gen HFE que se localiza en el cromosoma 6 y codifica la proteína HFE de 343 aminoácidos (15).

La anemia inflamatoria, ligada a enfermedades crónicas, es la segunda causa de anemia tras la debida a pérdidas de hierro; es consecuencia de la activación de citoquinas que median la respuesta inflamatoria e inmune y se caracteriza por la disminución de la disponibilidad del hierro para la eritropoyesis $(12,16)$. Recientemente se ha descrito la hepcidina humana como un reactante de fase aguda tipo II, mediador de la anemia inflamatoria y de la inmunidad innata $(8,17)$.

La hepcidina participa en la patogénesis de la hemocromatosis tipo 1, ligada a mutaciones del gen HFE, y puede modular la expresión de otros genes y mutaciones en el resto de enfermedades de sobrecarga de hierro no asociadas al gen HFE $(5,18)$. Así se ha descrito que el déficit de HFE determina una producción insuficiente de hepcidina $(7,19)$, por lo que ambos genes y proteínas deben estar relacionados (3). Además, se han identificado dos mutaciones en el gen de la hepcidina en dos familias que, en homocigosis, determinan un nueva forma de hemocromatosis juvenil tipo 2 (HFE2) (20) y que no siempre aparecen en este tipo de hemocromatosis que se sabe debida a mutaciones de un gen no indentificado pero localizado en el cromosoma 1q (21). Por otra parte, se han 
descrito pacientes con adenomas hepáticos que segregan hepcidina de forma inapropiada, denominados "hepcidinomas", y que provocan una anemia hipocroma de tipo inflamatorio refractaria al hierro, que se resuelve espontáneamente tras la resección de los adenomas (15).

Conocido que el déficit de hepcidina, asociado al de HFE, contribuye a la sobrecarga de hierro (8) y que el reestablecimiento de la producción de hepcidina en ratones con el gen HFE inactivado, evita el deposito de hierro (22), se admite la hipótesis de que la hemocromatosis es una enfermedad endocrina en la que la insuficiente producción por el hígado de hepcidina provoca una hiperabsorción crónica de hierro por el intestino y, por tanto, una sobrecarga del mismo (3). Por consiguiente, se puede proponer la utilización de hepcidina, de sus agonistas o de sustancias que estimulen su producción, como posible tratamiento de las enfermedades de sobrecarga de hierro tanto primarias como secundarias. A la inversa, los

\section{Bibliografía}

1. Krause A, Neitz S, Mägert HJ, Schultz A, Forssmann WG, SchulzKnappe P, Aderman K. LEAP-1, a novel highly disulfide-bonded human peptide, exhibits antimicrobial activity. FEBS Letters 2000; 480: 147-150.

2. Pigeon C, Ilyin G, Courselaud B, Leroyer P, Turlin B, Brissot P, Loreal $\mathrm{O}$. A new mouse liver-specific gene, encoding a protein homologous to human antimicrobial peptide hepcidin, is overexpressed during iron overload. J Biol Chem 2001; 276: 7811-7819.

3. Nicolas G, Kahn A, Vaulont S. L'hepcidine, chef d'orchestre de 1’homéostasie du fer. Presse Med 2003; 32: 1395-1396.

4. Loreal O, Brissot P. L'hepcidine: petite molécule, grands desseins. Rev Med InternA (Madrid) 2003; 24: 213-215.

5. Park $\mathrm{CH}$, Valore EV, Waring AJ, Ganz T. Hepcidin, an urinary antimicrobial peptide synthesized in the liver. J Biol Chem 2001; 276: 78067810 .

6. Merryweather-Clarke AT, Cadet E, Bomford A, Capron D, Viprakasit $\mathrm{V}$, Miller A et al. Digenic inheritance of mutations in HAMP and HFE results in different types of haemochromatosis. Hum Mol Genet 2003; 12: $2241-2247$.

7. Bridle KR, Frazer DM, Wilkins SJ, Dixon JL, Purdie DM, Crawford DHG et al. Disruptede hepcidin regulation in HFE-associated haemochromatosis and the liver as a regulator of body iron homeostasis. Lancet 2003; 361: 669-673.

8. Ganz T. Hepcidin, a key regulator of iron metabolism and mediator of anemia of inflammation. Blood 2003; 102: 783-788.

9. Altés Hernández A. Sobrecarga férrica. Algo más que hemocromatosis hereditaria. Med Clin (Barc) 2003; 120: 704-706.

10. Fleming DJ, Jacques PF, Tucker KL, Massaro JM, D’Agostino RB, Wilson PW et al. Iron status of the free-living, elderly Framinghan Heart Study cohort: an iron-replete population with a high prevalence of elevated iron stores. Am J Clin Nutr 2001; 73: 638-646.

11. Zúñiga Cabrera A, Orera Clemente MA. Genética de las sobrecargas férricas. An Med Interna (Madrid) 2002; 19: 195-201.

12. Dallalio G, Fleury T, Means RT. Serum hepcidin in clinical specimens. Br J Haematol 2003; 122: 996-1000.

13. Lee PL, Gelbart T, West C, Halloran C, Felitti V, Beutler E. A study of genes that may modulate the expression of hereditary hemochromatosis: antagonistas de la hepcidina podrían ser utilizados en el tratamiento de las anemias inflamatorias, resistentes a menudo a la eritropoyetina $(3,8)$.

En resumen, estamos ante una hormona de reciente conocimiento implicada en la regulación del metabolismo del hierro cuyo exceso determina anemia de enfermedades crónicas y su defecto enfermedades de sobrecarga de hierro y que podría, a su vez, ser utilizada para corregir estos trastornos mediante el empleo, según el caso, de sus antagonistas o agonistas.

\section{A. DEL CASTILLO RUEDA, J. DE PORTUGAL ÁLVAREZ}

\section{Servicio de Medicina Interna II. Hospital General} Universitario Gregorio Marañón. Madrid transferring receptor-1, ferroportin, ceruloplasmin, ferritin light and heavy chains, iron regulatory proteins (IRP)-1 and -2 , and hepcidin. Blood Cells Mol Dis 2001; 27: 518-529.

14. De Portugal Álvarez J. Hemocromatosis: del genotipo al fenotipo. An Med Interna (Madrid) 2002; 19: 163-165.

15. Del Castillo Rueda A, López-Herce Cid JA, De Portugal Álvarez J. Hemocromatosis hereditaria. Diagnóstico clínico: manifestaciones precoces, procesos relacionados y formas atípicas. An Med Interna (Madrid) 2002; 19: 251-256.

16. Weinstein DA, Roy CN, Fleming MD, Loda MF, Wolfsdorf JI, Andrews NC. Inappropriate expression of hepcidin is associated with iron refractory anemia: implications for the anemia of chronic disease. Blood 2002; 100: 3776-3781.

17. Nemeth E, Valore EV, Territo M, Schiller G, Lichtenstein A, Ganz T. Hepcidin, a putative mediator of anemia of inflammation, is a type II acute-phase protein. Blood 2003; 101: 2461-2461.

18. Bomford A. Genetics of haemochromatosis. Lancet 2002; 360: 16731681.

19. Gehrke SG, Kulaksiz H, Herrmann T, Riedel H-D, Bents K, Veltkamp $\mathrm{C}$, Stremmel W. Expression of hepcidin in hereditary hemochromatosis: evidence for a regulation in response to the serum transferring saturation and non-transferrin-bound iron. Blood 2003; 102: 371-376.

20. Roetto A, Papanikolaou G, Politou M, Alberti F, Girelli D, Christakis J et al. Mutant antimicrobial peptide hepcidin is associated with severe juvenile hemochromatosis. Nat Genet 2003; 33: 21-22.

21. Majore S, Binni F, Ricerca BM, Brioli G, Grammatico P. Absence of hepcidin gene mutations in 10 italian patients with primary iron overload. Haematologica 2002; 87: 221-222.

22. Nicolas G, Viatte L, Lou DQ, Bennoun M, Beamont C, Kahn A et al. Constitutive hepcidin expression prevents iron overload in a mouse model of hemochromatosis. Nat Genet 2003; 34: 97-101.

\section{BASES DE DATOS ELECTRÓNICAS}

Online Mendelian Inheritance in Man (OMIM): http://www.ncbi.nlm.nih. gov/Omim

GenBank: http://www.ncbi.nlm.nih.gov/Genbank/index.html 